\title{
Mössbauer studies of Gd-doped bismuth-based ceramic superconductors
}

\author{
E V SAMPATHKUMARAN ${ }^{\dagger}$, G WORTMANN* \\ and G KAINDL* \\ Tata Institute of Fundamental Research, Homi Bhabha Road, Bombay 400005, India \\ *Institut für atom-und Festkorperphysik, Freie Universitat Berlin, Arnimallee 14, Berlin 33. \\ FRG

\begin{abstract}
The results of ${ }^{155} \mathrm{Gd}$ Mössbauer studies (above $1.5 \mathrm{~K}$ ) of the oxides, $\mathrm{Bi}_{3.5} \mathrm{Gd}_{0.5} \mathrm{Ca}_{3} \mathrm{Sr}_{3} \mathrm{Cu}_{4} \mathrm{O}_{y}$ and $\mathrm{Bi}_{2} \mathrm{Sr}_{2} \mathrm{Ca}_{1-{ }_{x}} \mathrm{Gd}_{x} \mathrm{Cu}_{2} \mathrm{O}_{y}(x=0.25$ and 0.5$)$ are reported. The observed electric quadrupolar split resonance patterns suggest that $\mathrm{Gd}$ ions prefer to occupy $\mathrm{Ca}$ site in both series. The spectral features give evidence for paramagnetic relaxation of isolated $\mathrm{Gd}$ ions at low temperatures.
\end{abstract}

Keywords: Gd-Mössbauer; ceramic superconductors.

\section{Introduction}

The bismuth-based ceramic superconducting system, $\mathrm{Bi}-\mathrm{Ca}-\mathrm{Sr}-\mathrm{Cu}-\mathrm{O}$ (Maeda et al 1988) seems to behave similar to the $\mathrm{Y} \cdots \mathrm{Ba}-\mathrm{Cu}-\mathrm{O}$ system (Wu et al 1987) as far as the influence of rare-earth substitution (partially at the $\mathrm{Bi}$ site) on superconductivity is concerned (Sampathkumaran et al 1988; lkeda et al 1988). Our careful investigation of the series of compounds $\mathrm{Bi}_{4-x} \mathrm{RE}_{x} \mathrm{Ca}_{3} \mathrm{Sr}_{3} \mathrm{Cu}_{4} \mathrm{O}_{y}$ (with $\mathrm{RE}=\mathrm{La}$, Eu and Gd, $x \leqslant 0 \cdot 5)$ prepared under identical conditions shows that La suppresses the superconducting transition temperature $\left(T_{c}\right)$ as well as the superconducting volume fraction of this Bi-based superconductor much faster than $\mathrm{Eu}$ and $\mathrm{Gd}$ substituents; in the latter two cases, there is practically no variation of $T_{c}$ at all $(\simeq 65 \mathrm{~K})$. This is contrary to expectations from magnetic pair-breaking effects in conventional superconductors, but in conformity with the knowledge on $\mathrm{Y}-\mathrm{Ba}-\mathrm{Cu}-\mathrm{O}$ system. We explained this anomalous behaviour in terms of the influence of covalent mixing of extended $4 f$ ' wavefunction. While arriving at this conclusion, we (Ikeda et al 1988) argued on the basis of lattice constant measurements that the attempts to replace $\mathrm{Bi}$ by $R E$ result in the occupation of $R E$ at the $C a$ site. In order to put our views on a firm ground, we have carried out ${ }^{155} \mathrm{Gd}$ Mössbauer measurements on $\mathrm{Bi}_{3.5} \mathrm{Gd}_{0.5}$ $\mathrm{Ca}_{3} \mathrm{Sr}_{3} \mathrm{Cu}_{4} \mathrm{O}_{y}\left(T_{c} \simeq 65 \mathrm{~K}\right)$ as well as on $\mathrm{Bi}_{2} \mathrm{Sr}_{2} \mathrm{Ca}_{1-x} \mathrm{Gd}_{x} \mathrm{Cu}_{2} \mathrm{O}_{y}(x=0.25$ and 0.5 ; $y$-undetermined, $T_{c} \simeq 80 \mathrm{~K}$ and $T_{c} \simeq 20 \mathrm{~K}$ respectively). Preliminary results on some of these compounds have been communicated for publication (Wortmann et al 1989).

\section{Experimental}

The samples employed in the present investigation are the same as those used earlier (Sampathkumaran et al 1988, 1989). The ${ }^{155} \mathrm{Gd}$ Mössbauer experiments, using

\footnotetext{
${ }^{\dagger}$ For correspondence
} 
the $86.5 \mathrm{keV}(5 / 2 \rightarrow 3 / 2)$ gamma resonance, were performed in standard geometry at various temperatures between 1.5 and $80 \mathrm{~K}$ on sintered pellets $\left(600 \mathrm{mg} / \mathrm{cm}^{2}\right.$ thick), employing a liquid-helium cryostat and a sinusoidal Doppler drive for moving the source.

\section{Results and discussion}

Figure 1 displays ${ }^{155} \mathrm{Gd}$-Mössbauer spectra of $\mathrm{Bi}_{3 \cdot 5} \mathrm{Gd}_{0.5} \mathrm{Ca}_{3} \mathrm{Sr}_{3} \mathrm{Cu}_{4} \mathrm{O}_{y}$ at various temperatures. The spectra reveal an electric-quadrupole-split hyperfine pattern typical for the ${ }^{155} \mathrm{Gd}$ Mössbauer resonance (Wortmann et al 1987, 1988). There is clearly a main narrow-split quadrupole doublet (marked A) and a wider split much weaker component (marked B) visible in the spectra of figure 1 . We also checked our spectra for the absence of unreacted $\mathrm{Gd}_{2} \mathrm{O}_{3}$ in our specimen (to a few per cent) by taking into account the well-known Mössbauer spectrum of $\mathrm{Gd}_{2} \mathrm{O}_{3}$ (Cashion et al 1972) in the data analysis. From the careful least-squares fit analysis of the spectral shape of

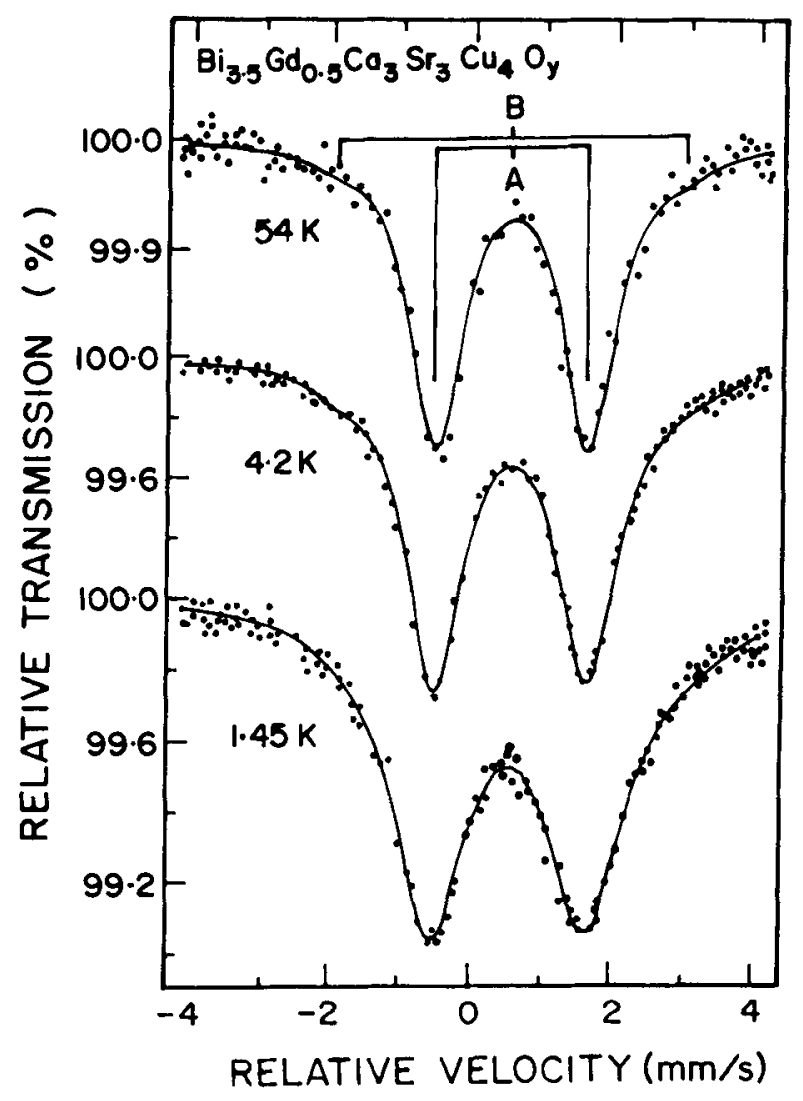

Figure 1. ${ }^{155} \mathrm{Gd}$-Mössbauer absorption spectra $\mathrm{Bi}_{3.5} \mathrm{Gd}_{0.5} \mathrm{Ca}_{3} \mathrm{Sr}_{3} \mathrm{Cu}_{4} \mathrm{O}_{y}$ at different temperatures. The intense doublet $\mathrm{A}$ indicating the splitting of the $I=3 / 2$ ground state and the weak doublet $B$ are indicated by vertical bars. The solid lines through the data points represent the results of least-square fits. 
the dominant quadrupole doublet, $\mathrm{A}$, we conclude that it consists of a superposition of at least three almost equally-split patterns, indicating a distribution of the electric field gradient by about $10 \%$ around the average value $V_{z z}=(-) 8.3 \times 10^{17} \mathrm{~V} / \mathrm{cm}^{2}$. The relative weight of the weak quadrupole doublet, $\mathrm{B}$, is about $6 \%$ and is characterized by $V_{z z} \simeq 18.5 \times 10^{17} \mathrm{~V} / \mathrm{cm}^{2}$. The above values of $V_{z z}$ were derived with $Q(3 / 2)=1.59$ barn for the electric-quadrupole moment of the ${ }^{155} \mathrm{Gd}$ nuclear groundstate. The linewidth of the dominating doublet, A, exhibits an increase with decreasing temperature (FWHM at $80 \mathrm{~K}: 0.88(10) \mathrm{mm} / \mathrm{s}$; at $54 \mathrm{~K}: 0.90(2) \mathrm{mm} / \mathrm{s}$; at $10 \mathrm{~K}: 1.00(6) \mathrm{mm} / \mathrm{s}$; at $4 \cdot 2 \mathrm{~K}: 1.04(2) \mathrm{mm} / \mathrm{s}$; and at $1.45 \mathrm{~K}: 1.40(4) \mathrm{mm} / \mathrm{s}$ ) as is seen in figure 1, particularly for the low-temperature spectra. This indicates the presence of paramagnetic relaxation of relatively isolated $\mathrm{Gd}$ ions when compared with concentrated systems like $\mathrm{Gd}_{2} \mathrm{O}_{3}$ (Cashion et al 1973). The observed isomer shift for the doublet $\mathrm{A}, \mathrm{S}=0.52 \mathrm{~mm} / \mathrm{s}$, is identical to that of $\mathrm{GdBa}_{2} \mathrm{Cu}_{3} \mathrm{O}_{7}$ (Wortmann et al 1987) and $\mathrm{Gd}_{2} \mathrm{O}_{3}$ (Cashion et al 1973). We also carried out $\mathrm{Gd}$ Mössbauer effect measurements on $\mathrm{Bi}_{3 \cdot 5} \mathrm{Gd}_{0 \cdot 5} \mathrm{Ca}_{3} \mathrm{Sr}_{3} \mathrm{Cu}_{4} \mathrm{O}_{y}$ and we do not observe (not shown in figure) the doublet with $V_{z z}=18.5 \times 10 \mathrm{~V} / \mathrm{cm}^{2}$.

We now present the results of our investigation on the specimens $\mathrm{Bi}_{2} \mathrm{Sr}_{2} \mathrm{Ca}_{1-x} \mathrm{Gd}_{x} \mathrm{Cu}_{2} \mathrm{O}_{y}$ in order to get an insight regarding the site occupation of $\mathrm{Gd}$ ions. The Gd Mössbauer spectra for two concentrations are shown in figures 2 and 3 at a few selected temperatures. For both the concentrations, essentially a single doublet is observed and the values of $V_{z z}$ are: $-8 \cdot 18(3) \times 10^{17} \mathrm{~V} / \mathrm{cm}^{2}$ for $x=0.25$ and $-7 \cdot 53(2) \times 10^{17} \mathrm{~V} / \mathrm{cm}^{2}$ for $x=0.5$. The marginal difference in the values of $V_{2 z}$ between these two concentrations may be associated with the differences in the lattice para-

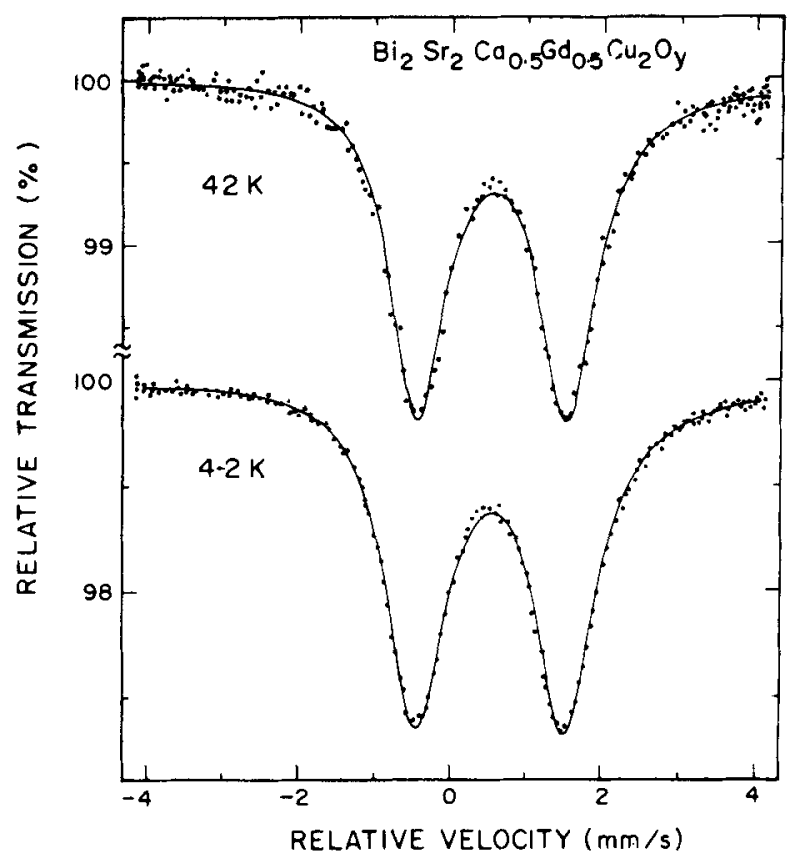

Figure 2. ${ }^{155} \mathrm{Gd}-\mathrm{Möss} b a u e r$ absorption spectra of $\mathrm{Bi}_{2} \mathrm{Sr}_{2} \mathrm{Ca}_{0.5} \mathrm{Gd}_{0.5} \mathrm{Cu}_{2} \mathrm{O}_{y}$ at different temperatures. 


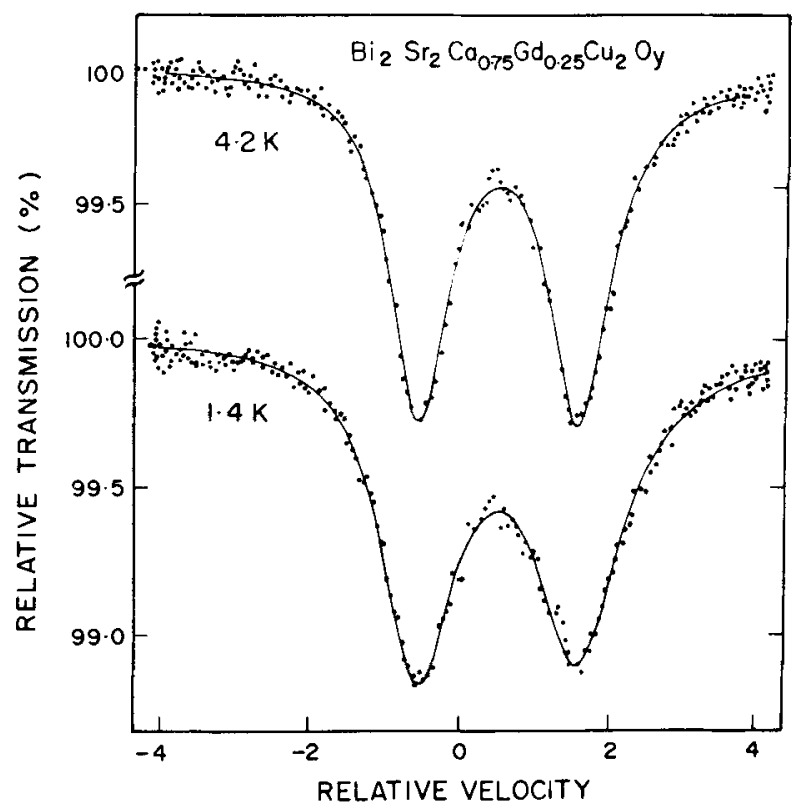

Figure 3. ${ }^{155} \mathrm{Gd}$-Mössbauer absorption spectra of $\mathrm{Bi}_{2} \mathrm{Sr}_{2} \mathrm{Ca}_{0 \cdot 75} \mathrm{Gd}_{0.25} \mathrm{Cu}_{2} \mathrm{O}_{y}$ at different temperatures.

meters, oxygen content, as well as carrier density concentration (Sampathkumaran et al 1989; Tamegai et al 1989). The essential point to be noted is that there is no evidence for the presence of another doublet in the Mössbauer spectra with a higher value of $V_{z z}$ and that the value of $V_{z z}$ for the intense component in $\mathrm{Bi}_{3 \cdot 5} \mathrm{Gd}_{0.5} \mathrm{Ca}_{3} \mathrm{Sr}_{3} \mathrm{Cu}_{4} \mathrm{O}_{y}$ is nearly the same as that observed in other specimens. Isomer shift values are also the same for all the specimens. These observations microscopically prove that the attempts to substitute $\mathrm{Gd}$ ion at the $\mathrm{Bi}$ site always result in the considerable occupation of this ion at the $\mathrm{Ca}$ site, in conformity with the conclusions from the lattice constants data (Ikeda et al 1989). The weaker component observed in $\mathrm{Bi}_{3.5} \mathrm{Gd}_{0 .} \mathrm{Ca}_{3} \mathrm{Sr}_{3} \mathrm{Cu}_{4} \mathrm{O}_{y}$ may, therefore, arise from those $\mathrm{Gd}$ ions occupying $\mathrm{Bi}$ site. From the non-observation of this feature in $\mathrm{Bi}_{3 \cdot 7} \mathrm{Gd}_{0 \cdot 3} \mathrm{Ca}_{3} \mathrm{Sr}_{3} \mathrm{Cu}_{4} \mathrm{O}_{y}$, we conclude that $\mathrm{Gd}$ initially prefers $\mathrm{Ca}$ site.

The occupation of $\mathrm{Gd}$ at the $\mathrm{Ca}$ site without depressing superconductivity (Sampathkumaran et al 1988) bears important consequences considering the crystallographic features of the Bi-based system. The $\mathrm{Cu}-\mathrm{O}$ layers, which are presumably responsible for superconductivity, are the nearest to $\mathrm{Ca}(\mathrm{Gd})$ layer. Therefore, the partial occupation of Gd ions in Ca layers does not seem to influence superconductivity as monitored by susceptibility and microwave absorption studies (Sampathkumaran et al 1989). This then means that superconductivity is not suppressed by the magnetic moments of localized $4 f$ electrons (in small concentrations) in this system. On the other hand, La doped in small concentrations under identical heattreatment conditions depresses superconductivity (Sampathkumaran et al 1988; Ikeda et al 1988). This depression of $T_{c}$ by La ions noted earlier by us may be attributed to the presence of more extended $4 f$ electronic states hybridizing with the ligand band, as proposed for the first time (Ikeda et al 1988; Neukirch et al 1988). This idea 
finds support in later investigations by various other groups (Kang et al 1989; Li et al 1989).

An analogous study was performed on an Eu-substituted $\mathrm{Bi}$ system, $\mathrm{Bi}_{3.5} \mathrm{Eu}_{0.5} \mathrm{Ca}_{3} \mathrm{Sr}_{3} \mathrm{Cu}_{4} \mathrm{O}_{y}$. We observed a single ${ }^{151} \mathrm{Eu}$ Mössbauer line with an isomer shift of $S=+0.70 \mathrm{~mm} / \mathrm{s}$ (with respect to the $\mathrm{SmF}_{3}$ source) that is typical for insulating trivalent $\mathrm{Eu}$ compounds. The analysis of the broadened and slightly asymmetric resonance line in terms of an electric-quadrupole interaction (as expected from the Gd system) resulted in a negative electric-field gradient, $V_{z z}=-5.0(5) \times 10^{17} \mathrm{~V} / \mathrm{cm}^{2}$. The absolute value of $V_{z z}(\mathrm{Eu})$ is roughly $2 / 3$ of that observed for the Gd system. We expect that the chemical environment of substituted $E u$ is the same as that of substituted $\mathrm{Gd}$. In case of $\mathrm{Gd}$, there is no contribution of the $4 f$ shell to $V_{z 2}$ due to the zero orbital angular momentum of the $S=7 / 2$ spin state. Therefore, $V_{z z}(\mathrm{Gd})$ represents exclusively the electric-field gradient of the lattice. The reduction of $V_{z z}$ in the Eu system is then consistent with a small $4 f$ contribution of the $J=2$ higher lying state of the $\mathrm{Eu}^{3+}$ ion, which amounts to roughly $1 / 3$ of $V_{z z}$ (lattice) and has the opposite sign (Bauminger et al 1973; Wortmann 1988).

\section{Acknowledgements}

The authors thank Dr A Kolodziejczyk for his help in the initial stage of the Mössbauer measurements. One of the authors (EVS) would like to acknowledge the encouragement by Prof. R Vijayaraghavan. This work was supported by the Bundesminister für Forschung and Technologie, project no. 13 N54842.

\section{References}

Bauminger E R et al 1974 Phys. Lett. A44 279; 50321

Cashion J D, Prowse D B and Vas A 1973 J. Phys. C6 2611 and references therein Ikeda N, Kohn K, Sampathkumaran E V and Vijayaraghavan R 1988 Solid State Commun. 6851 Kang J S et al 1989 J. Less Common Metals 148121

Li W H, Lynn J W, Skantha Kumar S, Clinton T W, Kebede A. Jee C S, Crow J E and Mihalisin T 1989 Phys. Rev. B40 5300

Maeda H, Tanaka Y, Fukutomi M and Asano T 1988 Jpn. J. Appl. Phys. 27 L209

Neukirch U, Simmons C T. Sladeczek P, Laubschat C. Strebel O, Kaindl G and Sarma D D 1988 Europhys. Lett. 5657

Sampathkumaran E V, Ikeda N, Kohn K and Vijayaraghavan R 1988 J. Phys. Lett. F18 L163

Sampathkumaran E V, Sastry M D and Kadam R M 1989 Physica C159 267

Tamegai T, Koga K, Suzuki K, Ichihara M, Sakai F, and Yasuhira I 1989 Jpn. J. Appl. Phys. 28 L112

Wortmann G, Simmons C T and Kaindl G 1987 Solid State Commun. 641057

Wortmann G, Blumenroder S, Freimuth A and Riegel D 1988 Phys. Lett. A126 434

Wortmann G, Sampathkumaran E V. Kaindl G and Kohn K 1989 Solid State Commun. (submitted)

Wu M K, Ashburn J R, Torng C J, Hor P H, Gao R L, Huang Z J, Wang Y Q and Chu C W 1987 Phys. Rev. Lett. $\mathbf{5 8} 908$ 